\title{
Health, Nutrition and Care for Senior Citizens of Nepal in Twenty First Century
}

\author{
${ }^{1}$ Sushil Adhikari \\ ${ }^{1}$ School of Health and Allied Sciences, Pokhara University, Kaski, Nepal
}

\begin{abstract}
Modernization has a greater impact over the population ageing from developed to developing countries. Nepal also could not remain untouched by it. Urbanization, social transformation and migration to immigration type of social phenomenon have been separating the family members. Not only that but also the desire of living with freedom and independent life has a powerful effect upon the life of senior citizens in Nepal. Lack of education, social security by government and sufficient income source of a notable population after 60 s is living under poor standard. The occupation of farming in the past used to be common in joint family life including very less number representing the high level business family. Where there was not such a problem of isolation and lack of nutrition and care for those citizens due to level of education. A large number living in the rural areas whether single or old couple has rare choice of food due to income even it is quite difficult to afford for simple medicine. The population of the less developed regions is ageing rapidly, too. Over the next four decades, the population aged 60 and over in the developing world is projected to triple from 473 million in 2009 to 1.6 billion in 2050. The older population itself is ageing at an accelerated rate with the population aged 80 and over projected to increase four-fold, to reach 395 million in 2050. The Second World Assembly on Ageing, which took place in Madrid, Spain, in April 2002, adopted the Madrid International Plan of Action on Ageing, to respond to the opportunities and challenges of population ageing in the twenty-first century and to promote the development of a society for all ages. In this context Nepal has to prepare a draft of own charter to address the issues of aging population.
\end{abstract}

Key words: Modernization, Population ageing, Developing countries, Health, Social Security.

Corresponding address: Sushil Adhikari, School of Health and Allied Sciences, Pokhara University, Kaski, Nepal. E-mail: adhikari.sushil11@gmail.com

\section{INTRODUCTION}

"A society for all ages encompasses the goal of providing older persons with the opportunity to continue contributing to society. To work towards this goal, it is necessary to remove whatever excludes or discriminates against them." The United Nations' 2002 Madrid International Plan of Action on Ageing (IPAA). ${ }^{1}$ Sudden spurt in the population of elderly in a country is bound to pose multiple challenges for the government. Developing countries are going to face such a growth in a much quicker time as compared to the developed world which saw such a demographic transition earlier. To face up to the coming challenges, the government of Nepal has to prepare its best to prepare for implementation of suitable policies and programs in future.

Recently, worldwide population agings have been considered one of the most important demographic phenomena. It is the product of clear decreases in birth and mortality rates and an increase in life expectancy, which is reflected in the socioeconomical progress of countries. The worldwide population aged 60 years and older will surpass from approximately 770 million in 2010 to an estimated one billion in 2020, and $20.0 \%$ of these people will be concentrated in developing countries. Thus, it needs to be addressed and proper attention should be given to the elderly people. ${ }^{2}$

Demographically, age of senior citizens can be classified into two clusters: (a) Active life (b) care life. Active life is productive age recognized up to 75 years and care life is 75 and beyond this. There is no retirement to be member of political parties, social workers and consultant and thus, many retired person has been practicing in consultant services to maintained their capacity and healthy environment.

Though the government of Nepal has defined the age of senior citizens over 60 years, there is some confusion in this definition. For example, on one hand Nepal demographic survey assumes that people over 60 years are senior citizens, on the other hand, the retirement age for civil servants is fixed at 58 years while for lower rank police and military personnel the retirement age varies from 44 to 46 though the retirement ages for higher level police and military officers range between 56 and 58 . For university professors, the age is fixed at 63 years and for judges it is 65 years. In recent days, depleting socio-cultural value system, diversification in occupation from agricultural to non-agricultural, higher mobility of economically active persons for seeking job and better education, and replacing existing joint family system by nuclear family system have been causing problematic for the security of aged people in Nepal. Much progress has been made in the quality and quantity of health care services in Nepal in the last few decades. However, improvements have been uneven with urban areas getting the best advantage of modern technological advances in Medicare. ${ }^{1}$

\section{Socio- economic conditions}

The majority of elderly in Nepal are living in rural areas (85 $\%^{+}$). They are usually active and productive in their advancing years doing things such as taking responsibilities for child care, cattle herding, handicrafts and many more. Among $65+$ 
years aged persons, $47.12 \%$ are found economically active with sex differential of $59.7 \%$ for males and $34.3 \%$ for females. This could be because women's contributions are generally not accounted for in market values. ${ }^{3}$

\section{Living arrangements of old people}

In Nepali tradition, sons are morally obligated to provide care and support to their parents. It is estimated that more than $80 \%$ of elderly in Nepal live with their children. Only $2.7 \%$ of the elderly in Nepal are living with their daughters which may be due to the cultural taboos that prevent parents from living with married daughters. Several studies in Nepal show that the long established culture and traditions of respecting elders are eroding day by day. Younger generations move away from their birthplace for employment opportunities elsewhere. Consequently, more elderly today are living alone and are vulnerable to mental problems like loneliness, depressions and many other physical diseases.

\section{Dependency ratio}

The elderly dependency rate computed for different time periods shows increasing trend from $7.5 \%$ in 1911 to $12.01 \%$ in 2001. Considering the time span of 90 years; the rate is very slow with the magnitude of only $0.05 \%$ increase per year. In 1961 , only $73.17 \%$ and $32.13 \%$ of the elderly male and females were married. This increased to $88.3 \%$ for male and $71.7 \%$ for females in 2009 . A study in 2002 revealed that about $9.11 \%$ of males and $24.94 \%$ of females are widowers/ widows. About $0.32 \%$ males and $0.50 \%$ females divorce with their life partners and live a single life. ${ }^{4}$

\section{Government initiatives}

The government started to include plans, policies and programmes for family-based security system to enable elderly to lead a dignified life since the Ninth Five Year Plan (1997-2002). Since then many initiatives have been taken focusing on the followings:

\section{Health}

The Nepalese Council of Ministers on 2061-05-03 BS adopted a guidelines entitled Jeshtha Nagarik Swashthopachar Sewa Karyakram Karyanyowan Nirdeshika 2061BS (Senior Citizens Health Facilities Program Implementation Guideline, 2061BS) which attempts to provide medical facilities to the old age people. ${ }^{5}$

The government has provision to establish Jeshtha Nagarik Swashthopachar Kosh (Senior Citizens Health Facilities Fund) in each district. Following the "Senior Citizens Health Facilities Program Implementation Guideline, 2061BS", the poverty affected elderly people are provided free medicine and treatment up to NRs.2000 at a time in all 75 districts from the fund. The Government has proclaimed through the budget speech of fiscal year 2066/67 that the government will provide free health service for heart and kidney patient of 75 years and above age. Even though, a reliable step is not taken yet in case of Nepal. The last fiscal year (2067/68) budget also has provision to establish one health center for the elderly "Aarogya Aashram" in each of the five development regions of the country. ${ }^{5}$

However, these schemes have limited coverage and the government is severely constrained by the financial, trained human resources and institutional capacity to provide the needed support and care for elderly.

\section{Social security services}

The government is providing Old-Age-Allowance (OAA) of Rs. 500 per month to people age 70 and above. The government provides Rs 500 per month for widow $60+{ }^{3}$ The allowances is managed by Ministry of Women, Children and Social Welfare and distributed through the local units of Ministry of Local Development at the village level. OAA provided by the state can put predictability into the lives of poor older people and their families by offering them a guarantee of a minimum standard of living for themselves and their families. And there is increasing evidence that this has transformed the economic behavior of poor families. It has also restored dignity to many older people who now live in deep poverty and are often treated as a burden by their families. ${ }^{5}$

OAA is another form of recognition for older people, but there is little understanding of the impact and access of the pension on older people. Is it valued by them? Does the pension have equal economic impact on all kinds of older people? Does it change the status of older people? Does it have any social impact? Who benefits the most from the pension? In order to answer these questions, a study has to be undertaken. The government has pension scheme for retired public servants and their widows and children. The government also adds $10 \%$ in the total pension amount to the pensioners who are aged 75 years and above. However, only less than $7 \%$ of elders in Nepal benefit from this pension system. Majority of the population receive no pension and must depend on family support and personal savings. ${ }^{5}$

\section{Old-age homes}

There is an Old Age Home in the premises of temple Pashupati Nath (Pashupati Bridrashram) for the destitute elders. Likewise in Devghat of Tanahun, Sitapaila of Kaski, dhangadi,Kailali and many other places in different communities have a common interest over the care of elderly citizens especially around urban areas being easy access of donors and many more in recent days. Ministry of Women, Children and Social Welfare operates the old-age home that has the capacity for only 230 elderly people. This is the only one shelter for elderly people run by the government which was established in 1976 as the first residential facility for elders. There are about 82 organizations registered with the government spread all over Nepal. These organizations vary in their organizational status (government, private, NGO, $\mathrm{CBO}$, personal charity), capacity, facilities, and the services they provide. Most of them are charity organizations. About 
1,500 elders are living in these old-age homes at present. These private organizations are providing services to elderly out of the individual's initiatives. The services are determined with the consent of the individual generosity. The services and care, virtually, do not include aspects that are essential to cater elderly in these Homes. Despite these initiatives, the Government does not have any official records on how many old age destitute people are taking shelter in these Old Age Homes (Briddhashrams). ${ }^{6,7,8}$

\section{Nutrition}

Poor nutritional status is a primary concern for the elderly. Nutritionally inadequate diets can contribute to or exacerbate chronic and acute diseases and hasten the development of degenerative diseases associated with aging. In the past, it has been difficult to determine the scope of nutritional problems among the aged; however, methods of assessing dietary intake have improved. Providing information on the relationship of socioeconomic and other factors to nutrient intake is basic to improving the health and well-being of the elderly. The International Conference on Nutrition (ICN) held in Rome was the milestone in preparation and adoption of the Plan of Action for Nutrition. The plan of action recommended the areas for nutrition intervention for the countries. The areas that were identified for nutrition intervention are: starvation and famine; widespread chronic hunger; undernutrition, especially among children, women and the aged; micronutrient deficiencies; diet related communicable and non-communicable diseases; impediments to optimal breast feeding; and unsafe drinking water. ${ }^{7,9}$

Besides other many reasons, there is still a lack of comprehensive studies of the health and nutritional state and the quality of life of elderly people in Nepal. However, there are still major gaps in our knowledge of the profiles of nutritional status, pattern of intake, and health status of the elderly in most of Asian countries in general and Nepal in particular. ${ }^{10}$

\section{REFERENCES}

1. Political Declaration and Madrid International Plan of Action on Ageing. Second World Assembly on Ageing, Madrid, Spain, 8-12 April 2002.

2. César GG, Sergio SG, Teresa JC, Oscar RC, Luis M GR, Carmen GP. Health care utilization in the elderly Mexican population: Expenditures and determinants. BMC Public Health. 2011; 11:192.

3. Pawan A. The Situation of Population Ageing and Social Security for Elderly People in Nepal Health Prospect $2011 ; 10$.

4. Status Report on Elderly People (60+) in Nepal on Health, Nutrition and Social Status Focusing on Research Needs, Geriatric Center Nepal Ramchandra Marg, Battisputali-9 Kathmandu Nepal. March, 2010.

5. His Majesty's Government National Planning Commission Kathmandu, Nepal. THE TENTH PLAN (Poverty Reduction Strategy Paper-2002-2007) May 2003.

6. Ministry of Health and Population (MOHP) Nepal, New ERA, and Macro International Inc. 2007.

7. Nepal Demographic and Health Survey. Kathmandu, Nepal: Ministry of Health and Population, New ERA, and Macro International Inc. 2006.

8. Chalise HN. Demographic situation of population ageing in Nepal. Kathmandu Univ Med J (KUMJ). 2006 Jul-Sep; 4(3):354-62.

9. Geriatric Center Nepal (GCN). Sammanit Byaktitwaharu, 2066. Battisputali, Kathmandu, Nepal. 2009.

10. Impact on Food Production and Consumption. vol 1, Issue 1. Retrieved on March 3, 2010. fromhttp://www.un.org.np/ reports/HKI/2001/Nep_Nutr_Bul_vol1_iss1.pdf.

\section{RECOMMENDATION} conducted on the present status of senior citizens living within and outside the family, institutions and geriatric homes.

1. Identify the human and other resources need of MoPH for building the capacity for effective design and

. Program for short and long term training and study tours and volunteering packages for the key government officials in universities, training institutes abroad should support from the national and international institutions in the government and non-government sectors including $\mathrm{WB}, \mathrm{ADB}, \mathrm{DFID}$ and other INGOs working in health

In-country training programs for the district and VDC level health workers on caring of elders and run such

health education system of the country to incorporate emphasis. Work with Universities and colleges for the purpose.

5. Strengthen National Health Training Center for the purpose of training health practitioners (nurses), health Educational programs to enhance the effectiveness of health professionals, social workers and community careers, occupations, family situations or vocational interests involve interaction with older people should be developed.

6. Work with international and bilateral agencies in general and procedural development to implement the current National Plan of Action on Ageing guided by the MIPAA. to oversee programs on ageing population and their proper care and counseling. and with UN agencies in particular for institutional 